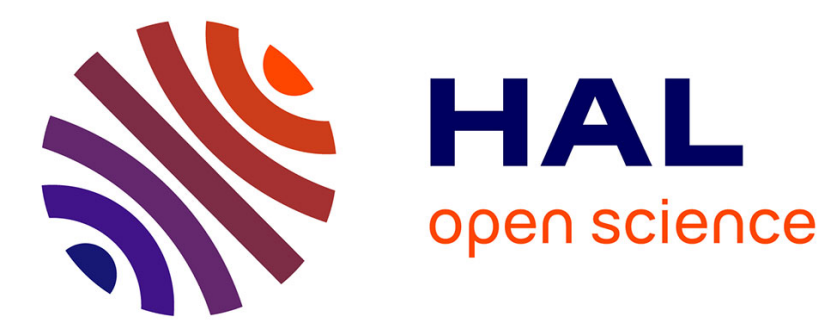

\title{
Investigations of Inducers Operating with High Rotational Speed
}

\author{
Björn Gwiasda, Matthias Mohr, Martin Böhle
}

\section{To cite this version:}

Björn Gwiasda, Matthias Mohr, Martin Böhle. Investigations of Inducers Operating with High Rotational Speed. 17th International Symposium on Transport Phenomena and Dynamics of Rotating Machinery (ISROMAC2017), Dec 2017, Maui, United States. hal-02390272

\section{HAL Id: hal-02390272 \\ https://hal.science/hal-02390272}

Submitted on 2 Dec 2019

HAL is a multi-disciplinary open access archive for the deposit and dissemination of scientific research documents, whether they are published or not. The documents may come from teaching and research institutions in France or abroad, or from public or private research centers.
L'archive ouverte pluridisciplinaire HAL, est destinée au dépôt et à la diffusion de documents scientifiques de niveau recherche, publiés ou non, émanant des établissements d'enseignement et de recherche français ou étrangers, des laboratoires publics ou privés. 


\title{
Investigations of Inducers Operating with High Rotational Speed
}

\author{
Björn Gwiasda ${ }^{1 *}$, Matthias Mohr ${ }^{1}$, Martin Böhle ${ }^{1}$
}

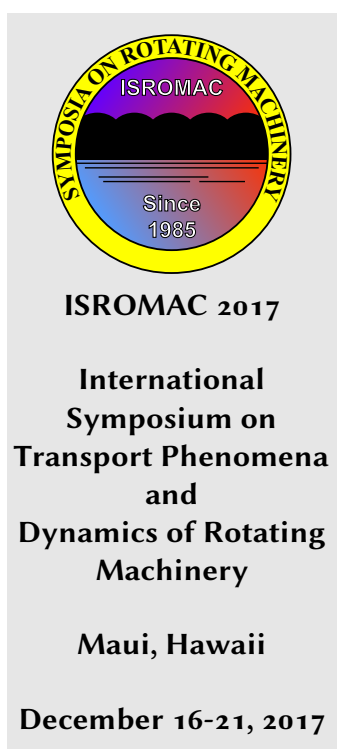

\begin{abstract}
Suction performance, pressure rise and efficiency for four different inducers are examined with CFD simulations and experiments performed with $18000 \mathrm{rpm}$ and $24000 \mathrm{rpm}$. The studies originate from a research project which includes the design of a new test bench in order to judge the design of the different inducers. This test bench allows to perform experiments with a rotational speed of up to $40000 \mathrm{rpm}$ and high pressure ranges with water as working fluid. Experimental results are used to evaluate the accuracy of the simulations and to gain a better understanding of the design parameter. The influence of increasing the rotating speed from $18000 \mathrm{rpm}$ to $24000 \mathrm{rpm}$ on the performance is also shown.

\section{Keywords}

Inducer - Cavitation - Performance

${ }^{1}$ Institute of Fluid Mechanics and Fluid Machinery, Department of Mechanical and Process Engineering, University of Kaiserslautern, Kaiserslautern, Germany

*Corresponding author: gwiasda@mv.uni-kl.de
\end{abstract}

\section{INTRODUCTION}

The inducer is a component of hydraulic fluidmachinery that is typically applied in turbopumps of liquid fuel rocket engines that operate at high rotational speeds. It belongs to the group of axial flow impellers and can be characterized by high solidities and very small blade angles. A lot of information on the hydraulic design and the characteristics of this type of impeller can be found in textbooks well known in the field of turbomachinery, e.g. $[1,2,3]$. Although many design guidelines for inducers exist, especially a reliable prediction of the suction performance of inducers still remains an unresolved issue. Therefore the design process of inducers has to rely on numerical and experimental methods that ensure the compliance of the new design with the requirements. The prediction of the non cavitating hydraulic performance is described in [4] for example. While it is widely accepted that CFD can be used to estimate and evaluate the performance characteristics of fluidmachinery under non-cavitating conditions, the prediction of the suction performance is a task fraught with uncertainty because of the modeling involved when simulating the cavitating flow. Hence the comparison of the numerical results with experimental data is still a mandatory job. As liquid rocket engine turbopumps are operated with cryogenic fluids a typical approach to significantly reduce the cost and effort needed when handling these fluids is to use water as the working fluid for the experimental investigation [5]. How the results of such tests can be transferred to the real application has recently been adressed by the authors of [6] and [7]. The authors have developed an elaborate testbench that uses heated water to validate a method to consider thermal effects on the cavitation phenomena occuring in inducers for turbopumps. Descriptions of two other sophisticated testbenchs that are used to investigate rotordynamic phenomena in turbopumps attributed to inducers and their interaction with the surrounding pump components can be found in [8] and [9]. All of the aforementioned test configurations have in common that they operate at lower rotational speeds than can be found in the real application. As a part of a research project granted by the German Aerospace Center (DLR) a new water testbench that allow tests with high rotational speeds has been developed at the Technical University of Kaiserslautern (TU Kaiserslautern). In the course of this project four inducers with differences in hub shape and blade angle distribution have been designed. One requiremente of the project is to test the inducers as close as possible to the design speed of $24000 \mathrm{rpm}$. To avoid premature damages of the prototype as well as the test bench equipment a first series of measurements at $18000 \mathrm{rpm}$ are conducted. A detailed comparison between the results of simulations and experiments for the four inducers is performed. In particular the influence of the design details on the obtained performance characteristics is discussed. Also the influence of rotational speed on performance is addressed. 


\section{METHODS}

In this section an overview of the methods used in the remainder of the current paper is given. First the parameters that are used to calculate and visualize the hydraulic and suction characteristics are introduced. In section 1.2 details about the design are given. Performance and suction characteristics for a rotational speed of $n=18000 \mathrm{rpm}$ are obtained numerically and experimentally for all of the designed inducer variants. Details of the numerical and experimental setups are presented in section 2 and 3 respectively. Section 4 includes a detailed comparison of these results and an interpretation of the influence of the blade design on performance and suction behavior. Furthermore the same set of data is presented for inducer variant Ao (see table 2) at the rotational speed $n=24000 \mathrm{rpm}$ and the influence of the change in speed is discussed.

\subsection{Performance Parameters}

To ensure comparability of the data when matching the numerically calculated quantities against the ones obtained by the test runs the following formulas for Head $H$, efficiency $\eta$ and net positive suction head NPSH are applied:

$$
\begin{aligned}
H & =\frac{p_{2}-p_{1}}{\rho g}+\frac{c_{2}^{2}-c_{1}^{2}}{2 g} \\
\eta & =\frac{Q \rho H g}{M \omega} \\
N P S H & =\frac{p_{1}-p_{v}}{\rho g}+\frac{c_{1}^{2}}{2 g}
\end{aligned}
$$

Indices 1 and 2 denote the positions of the evaluation planes in case of the numerical simulation which are located at the same axial coordinates as the pressure taps in the experimental setup. The velocities are calculated as function of the corresponding cross sectional area as follows:

$$
c_{1}=\frac{Q}{A_{1}}, \quad c_{2}=\frac{Q}{A_{2}}
$$

With $u_{t}=\pi D_{t} n$ being the blade tip speed and $c_{L E}=\frac{Q}{\frac{\pi}{4}\left(D_{S}^{2}-D_{L E, h}^{2}\right)}$ the following representations of head, flow and cavitation coefficient are obtained:

$$
\begin{aligned}
\Psi & =\frac{2 H g}{u_{t}^{2}} \\
\varphi & =\frac{c_{L E}}{u_{t}} \\
\sigma_{c} & =\frac{2 g N P S H}{u_{t}^{2}}
\end{aligned}
$$

Furthermore the dimensionless form of suction specific speed $\Omega_{s s}$ according to [2] is employed:

$$
\Omega_{s S}=\omega \frac{\sqrt{Q}}{(g N P S H)^{3 / 4}}
$$

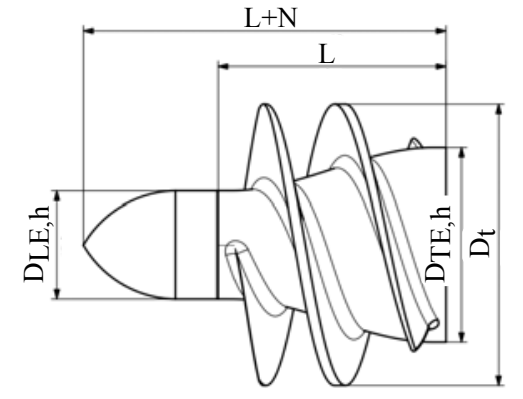

Figure 1. Main dimensions of the inducers

\subsection{Inducer Designs}

An institute-owned design procedure is used to design the four inducers under consideration. The design parameters and additional requirements that had to be satisfied are summarized in table 1. All inducers are designed to operate at a rotational speed of $n_{d}=24000 \mathrm{rpm}$ and a flow coefficient of $\varphi_{d}=0.1$. The head coefficient $\psi_{d}$ has intentionally been treated as a free parameter to gain a better understanding of the influence of the geometrical variations on the head and efficiency characteristics. Figure 1 shows a drawing that illustrates the parameters used to describe the main dimensions of the inducers. Although the operating conditions have been derived from a real turbopump application there is only an academic interest in the investigations. Based on the operating conditions the design of the inlet eye has been predetermined by the specification of the hub diameter $D_{1 h}$ at the leading edge and the diameter of the cylindrical shroud $D_{s}$ according to table 1 . The tip clearance amounts to $0.3 \mathrm{~mm}$, which leads to a tip clearance area that is smaller than $3 \%$ of the flow area as recommended in [5]. With the inlet geometry and the flow coefficient predefined the theoretically obtainable suction specific speed according to Brumfields equation (see e.g. [5]) is also predetermined. For the given inflow conditions one can estimate $\Omega_{S S, d} \approx 12$ or expressed in terms of cavitation number $\sigma_{c, d} \approx 0.03$. The blade angle along

Table 1. Design Parameters - common to all variants

\begin{tabular}{ccc}
\hline Parameter & Unit & Value \\
\hline Number of blades & - & 2 \\
$D_{L E, h}$ & $\mathrm{~mm}$ & 20 \\
$D_{S}$ & $\mathrm{~mm}$ & 52.7 \\
$D_{t}$ & $\mathrm{~mm}$ & 52.1 \\
$i / \beta_{b, L E}$ & - & 0.425 \\
$\beta_{b, L E, h}$ & $\circ$ & 25.7 \\
$\beta_{b, L E, t}$ & $\circ$ & 10.1 \\
$\Delta \Theta_{t}$ & $\circ$ & 75 \\
\hline
\end{tabular}

the blade leading edge has been designed by application of a constant ratio of incidence to blade angle $i / \beta_{b, L E}=0.425$. This leads to the blade angles at the hub and shroud diameter listed in table 1 . To realize the targeted suction performance a sweep back of the leading edge is performed according to 
the results in [10]. The value used for the sweep back angle at the tip diameter is $\Delta \Theta_{t}=75^{\circ}$. Furthermore the sharpening of the leading edge suction surface is accomplished by setting the ratio of wedge angle to blade angle $\alpha_{w} / \beta_{b, L E} \approx 1 / 3$. By the application of the aforementioned details the resulting blade angle, wedge angle and incidence angle at the leading edge tip lie quite well in the range of the historical data summarized in [11]. While the parameters discussed until

Table 2. Specific design parameters

\begin{tabular}{cccccc}
\hline & & \multicolumn{4}{c}{ Value } \\
\cline { 3 - 6 } Parameter & Unit & Ao & Mo & M1 & M2 \\
\hline$L$ & $\mathrm{~mm}$ & 45 & 41.1 & 42.1 & 42.1 \\
$D_{T E, h}$ & $\mathrm{~mm}$ & 20 & 36 & 36 & 36 \\
$\beta_{b, T E, h}$ & $\circ$ & $25 \cdot 7$ & 14.5 & 21.9 & 27.5 \\
$\beta_{b, T E, t}$ & $\circ$ & 10.1 & 10.1 & 13.1 & 13.1 \\
\hline
\end{tabular}

now are equal for all the inducers under investigation, the parameters listed in table 2 give an overview of the differences in their geometrical details. The designed inducers are named Ao, Mo, M1 and M2. As can be seen from table 2 the inducer variants differ in their axial length $L$. A more significant difference can be observed in terms of the hub shape of the inducers. The hub diameter of variant Ao is constant, that is $D_{h, L E}=D_{h, T E}$, whereas the hub diameter increases from $20 \mathrm{~mm}$ to $36 \mathrm{~mm}$ for the remaining variants starting with letter $M$. The hub shape for inducer Mo, M1 and $\mathrm{M} 2$, to increase the hub diameter, is the same. Furthermore the variants Ao and Mo basically feature the same blade design without any change in blade angle with respect to the axial direction. In contrast the remaining variants $\mathrm{M}_{1}$ and $\mathrm{M} 2$ can be characterized by a variable blade angle distribution. While the change in blade angle is equal on the tip section for both designs the trailing edge blade angle at the hub for the inducer $\mathrm{M}_{1}$ is smaller than the exit blade angle of variant M2. The four inducers have been manufactured in the university-owned workshop by CNC milling and turning. Figure 2 depicts the prototypes made out of a high-strength aluminum alloy 3.4345 suitable for the test in water.

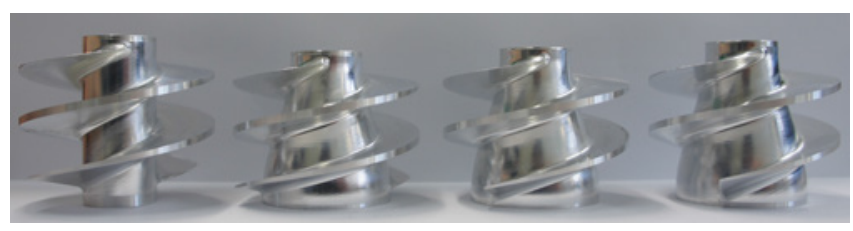

Figure 2. Inducers - from left to right: Ao, Mo, $M_{1}, M_{2}$

\section{NUMERICAL SETUP}

The simulation model is shown in figure 3. Only one passage is used to perform the simulations. Rotational periodicity is used as an interface where the periodic faces would connect to the other passage. The whole model consists of three domains: inlet, inducer and outlet. They are connected by a frozen rotor interface. All domains are discretized with hexahedral grids. For inlet including the nose ANSYS ICEM CFD is used to generate the mesh. The inducer and outlet domain is created with ANSYS TURBOGRID. Computations are performed with ANSYS CFX 16.2. Locations $\mathrm{P}_{1}$ and $\mathrm{P}_{2}$ mark the planes where the physical data of the results are evaluated. As already mentioned the distance of the planes to the inducer domain are consistent to the positions where the pressure is measured in the experimental setup. INLET denotes the inflow and OUTLET the outflow regions of the simulation model.

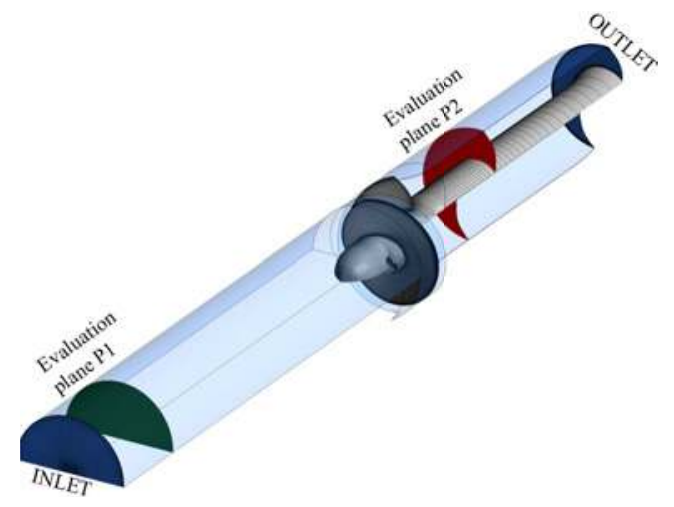

Figure 3. Simulation model

Two different sets of simulations are performed for each inducer. One to evaluate performance and one for suction performance. The following simulation settings are used for both procedures. A total pressure boundary condition is defined at the inlet. At the outlet a mass flow is set. The length between inlet and inducer is $4 D_{s}$ and $3 D_{s}$ from Inducer to the outlet. The turbulence model used is SST. The advection scheme is set with high resolution and the turbulence numeric with first order. Single phase simulations are performed to obtain the performance characteristics. In the case of the simulation of the suction performance curves liquid and vapor phase are used. For this simulation the cavitation option in mass transfer is enabled. Cavitation is modeled by the built-in rayleigh-plesset model. To allow CFX the use of a wall function to describe the flow with the SST model $y^{+}$is chosen appropriately. A schematic view of the mesh on the surface of the inducer Ao as an example is shown in figure 4

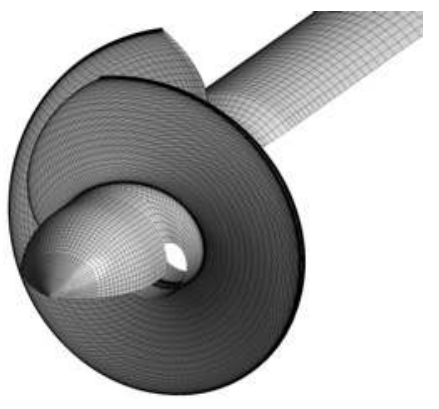

Figure 4. Inducer

For all inducers 11 elements are used inside the tip clearance. Approximately 300000 elements are used to describe 
the inducer passage. The total mesh including inlet and outlet consists of around 500000 elements.

\section{EXPERIMENTAL SETUP}

Figure 5 shows a hydraulic plan of the test rig at the TU Kaiserslautern. The design is based on the experience described of Gülich [12]. There are two possible modes of operation marked with red and blue. The red line shows the flow in the case of closed loop operation and blue in the case of operation with open loop. In the latter case there is flow through the tank. For the closed loop configuration the shut off valves at the tank are closed. To regulate the inlet pressure during operation with closed loop a small connection between tank and the suction pipe with a small tube is used to imprint the pressure inside the tank on the intake section. Especially to measure the suction performance at low inlet pressure the closed loop operation (red line) is recommended in literature [12]. A dissolved oxygen sensor is implemented to ensure comparable conditions for each measurement. To observe vibrations an acceleration sensor is implemented at the intake pipe near the inducer. 40 bara is the maximum possible pressure at the inducer outlet. Inside the tank the pressure can be adjusted from 0.1 bara to 6 bara. To compensate the pressure losses in pipes and components a booster pump is installed. This allows for operation at high overload, that means high volume flows. In the suction pipe of the inducer the temperature is measured. The torque meter is placed between the drive motor and the inducer shaft. As mentioned before the working fluid is water.

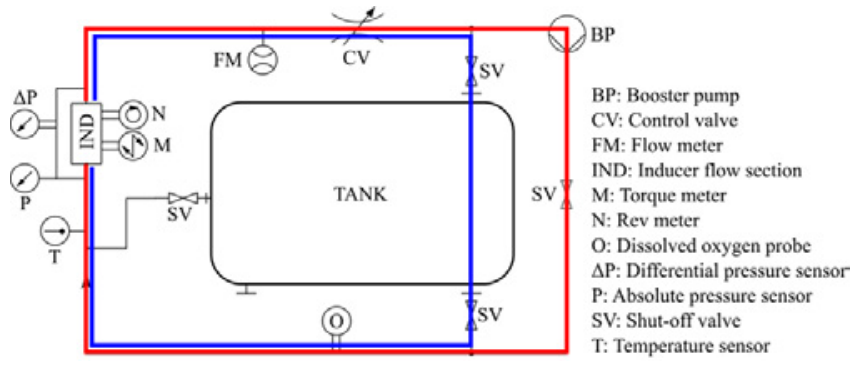

Figure 5. Hydraulic plan

Figure 6 gives a detailed view of the measurement section. $\mathrm{P}_{1}$ and $\mathrm{P}_{2}$ mark the positions where the pressure is measured. According to standard 9906 [13] the static pressure is measured with four holes distributed uniformly at the circumference. Distance $L_{1}$ is a function of $D_{s}$ with $L 1 \approx 3.5 \cdot D_{s} . L_{2}$ is constant due to construction conditions with $L_{2} \approx 50 \mathrm{~mm}$. To get visual access the inducer casing is made out of acrylic glass. A steady view of the rotating impeller is realized with by using a stroboscope which is synchronized with the actual rotating frequency. The pictures and videos at each measured point are taken with a HD networkcam so that a real time look at the inducer is possible during the measurement. Table 3 lists the sensors with the corresponding measurement ranges utilized at the test bench. An inlet pressure of $p_{t o t, 1}=4$ bara is realized during performance measurements to avoid the influence of cavitation effects.
Table 3. Sensors

\begin{tabular}{lccl}
\hline Sensor & Symbol & Unit & Range (Error) \\
\hline Torque meter & $\mathrm{M}$ & $\mathrm{Nm}$ & $0 \ldots 10(\mathrm{o} .1 \%)$ \\
Revolution counter & $\mathrm{n}$ & $\mathrm{rpm}$ & $0 \ldots 60000(-)$ \\
Absolute pressure & $\mathrm{P}_{1}$ & $\mathrm{bara}$ & $0 \ldots 10(\mathrm{o} .04 \%)$ \\
Difference pressure & $\mathrm{P}_{2}-\mathrm{P} 1$ & $\mathrm{bar}$ & $0 \ldots 20(\mathrm{o.04 \%})$ \\
Temperature at intake & $\mathrm{T}$ & $\mathrm{K}$ & $223 \ldots 673(-)$ \\
Flow meter & $\mathrm{Q}$ & $\mathrm{m}^{3} \mathrm{~h}^{-1}$ & $0 \ldots 120(\mathrm{o.4} \%)$ \\
\hline
\end{tabular}

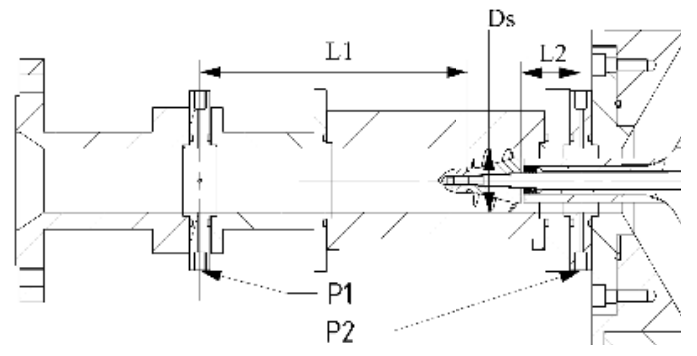

Figure 6. Measurement section

\section{RESULTS}

\subsection{Comparison of CFD and experiment}

Figure 7 gives an overview of all the characteristic curves obtained by experiment and CFD simulation at a rotating speed of $18000 \mathrm{rpm}$ for every inducer. Each plot shows the comparison of experimental and numerical result in dimensionless form. Experiment and simulation are compared looking at the head coefficient and the efficiency both as a function of the flow coefficient. To describe the suction performance a normalized head coefficient is used and plotted against cavitation number $\sigma_{c}$. The normalized head coefficient is defined as the head coefficient at the actual cavitation number $\psi_{\sigma_{c}}$ referenced to the head coefficient occurring at the maximum cavitation number $\psi_{\sigma_{c, \max }}$. Head coefficient and efficiency of the experimental results confirm the CFD simulation very good at the design point of $\varphi=0.1$. For minor partial load the head coefficient also show a good accordance for all inducers. It can be seen that at heavy partial load conditions the results of CFD and experiments start to differ. For the axial inducer Ao this effect is much more distinct. In overload the results of CFD and experiments match very good. Close to the design point efficiency matches quite good. While in overload the simulation tends to overpredict the efficiency, the tendency in part load is vice-versa. Especially in case of inducer Ao this is strongly pronounced and clearly visible. Furthermore it is evident that only inducers $\mathrm{M}_{1}$ and $\mathrm{M}_{2}$ are operating close to their point of best efficiency at design volume flow. Looking at the results for suction performance inducer Ao, $M_{1}$ and $M_{2}$ show a very good agreement between CFD and experiment. Between $\sigma_{c} \approx 0.15$ and $\sigma_{c} \approx 0.05$ a first drop of head coefficient can be observed looking at the experimental results for all inducers. Pulsation effects could be observed in this range during experiments. This unsteady effects are not taken into account by the steady simulations and because 
only one passage is used to perform the simulation. To catch instabilities with the simulation a full transient $3 \mathrm{D}$ simulation is necessary. The head coefficient for inducer Mo increases with decreasing cavitation number before the first drop in head coefficient occurs in experiment. This effect can only be observed looking at inducer Mo. For inducer Ao, M1 and $\mathrm{M} 2$ the results of CFD and experiments have nearly the same progression before the first drop in head coefficient occurs. To evaluate the suction performance $10 \%$ drop of head coefficient is chosen as the cavitation criterion in accordance to the historical data given in [5]. Table 4 shows the value of $\sigma_{c}$ and $\Omega_{s s}$ where the head coefficient lost $10 \%$ compared to the head coefficient at maximum cavitation number. The drop in head coefficient occurs at nearly the same value for $\sigma_{c}$ in the experiments and the CFD simulations for inducer Ao, M1 and M2. As mentioned before the difference between CFD and experiment is higher for inducer Mo. The first drop in head coefficient is much more pronounced. The estimated $\Omega_{s s} \approx 12$ during the design procedure is in good accordance to the values obtained by experiments, at least for the inducers Ao, M1 and M2. In all cases CFD overestimates suction performance.

Table 4. $\sigma_{c}$ at a drop of $10 \%$ head coefficient

\begin{tabular}{cccccc}
\hline Inducer & \multicolumn{2}{c}{ CFD } & \multicolumn{2}{c}{ EXP } \\
\hline & $\sigma_{c}$ & $\Omega_{s s}$ & $\sigma_{c}$ & $\Omega_{s s}$ & $n / \mathrm{rpm}$ \\
\cline { 2 - 6 } Ao & 0.022 & 15.44 & 0.032 & 11.67 & 18000 \\
Ao & 0.023 & 14.94 & 0.028 & 12.89 & 24000 \\
Mo & 0.026 & 13.62 & 0.071 & 6.41 & 18000 \\
M1 & 0.023 & 14.94 & 0.031 & 11.94 & 18000 \\
M2 & 0.025 & 14.03 & 0.028 & 12.89 & 18000 \\
\hline
\end{tabular}

\subsection{Comparison of inducers}

The influence of the different inducer designs on head coefficient and efficiency may be seen in figure 8 and 9 . Where experimental results at $n=18000 \mathrm{rpm}$ are compared for all inducers. Comparing the axial version Ao and version Mo without changing the blade angle distribution at the trailing edge a subsidence in efficiency and head coefficient level can be observed. The slope for Ao is also flatter than for Mo looking at the head coefficient. Taking the design Point at $\varphi=0.1$ as a reference the point of best efficiency is in overload for Ao. For Mo the point of best efficiency shifts to partial load. Changing the blade angle distribution at the trailing edge an increase in head coefficient and efficiency can be observed by comparing $\mathrm{M}_{1}$ and $\mathrm{M}_{2}$ to Mo. Also the point of best efficiency is closer to the design point for inducer $\mathrm{M}_{1}$ and $\mathrm{M}_{2}$. Comparing $\mathrm{M}_{1}$ and $\mathrm{M}_{2}$ latter has a slightly higher level in head coefficient and efficiency. Looking at the suction performance in figure 10 we can see that the point a first drop in head coefficient occurs is almost the same for all inducers $\sigma_{c} \approx 0.1$. The first drop of head coefficient is not this distinctive for M1 and M2 compared to Mo and Ao. The drop is most pronounced for inducer Mo which differs from
Ao only by its hub shape. Clearly the data summarized in table 4 shows that there's an substantial offset between the suction performance predicted by CFD and the one obtained by experiment. Furthermore the trend of the experimental results is not represented by the simulation data.

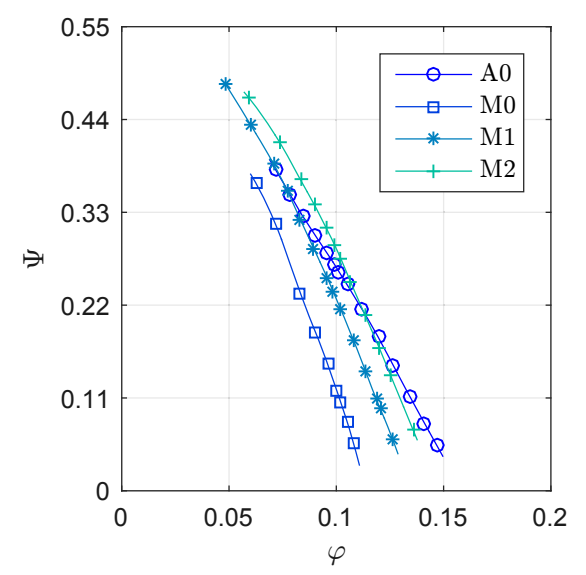

Figure 8. Head coefficient at $18000 \mathrm{rpm}$ (Experiment)

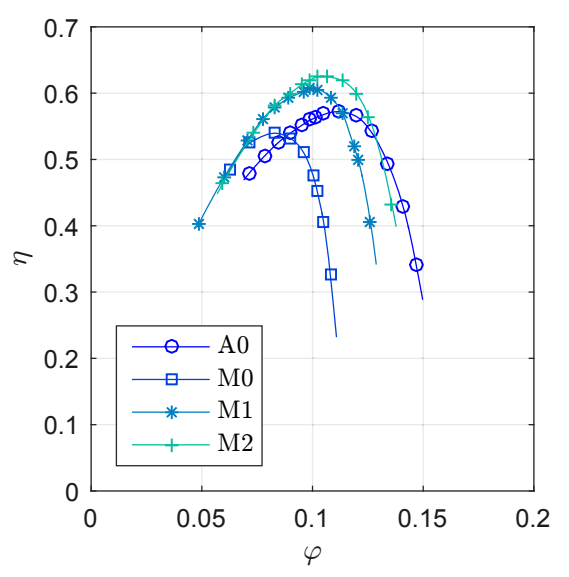

Figure 9. Efficiency at $18000 \mathrm{rpm}$ (Experiment)

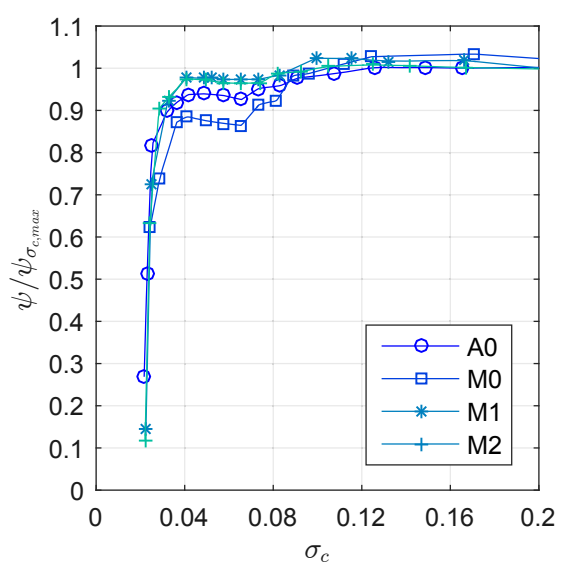

Figure 10. Suction performance at $18000 \mathrm{rpm}$ (Experiment) 

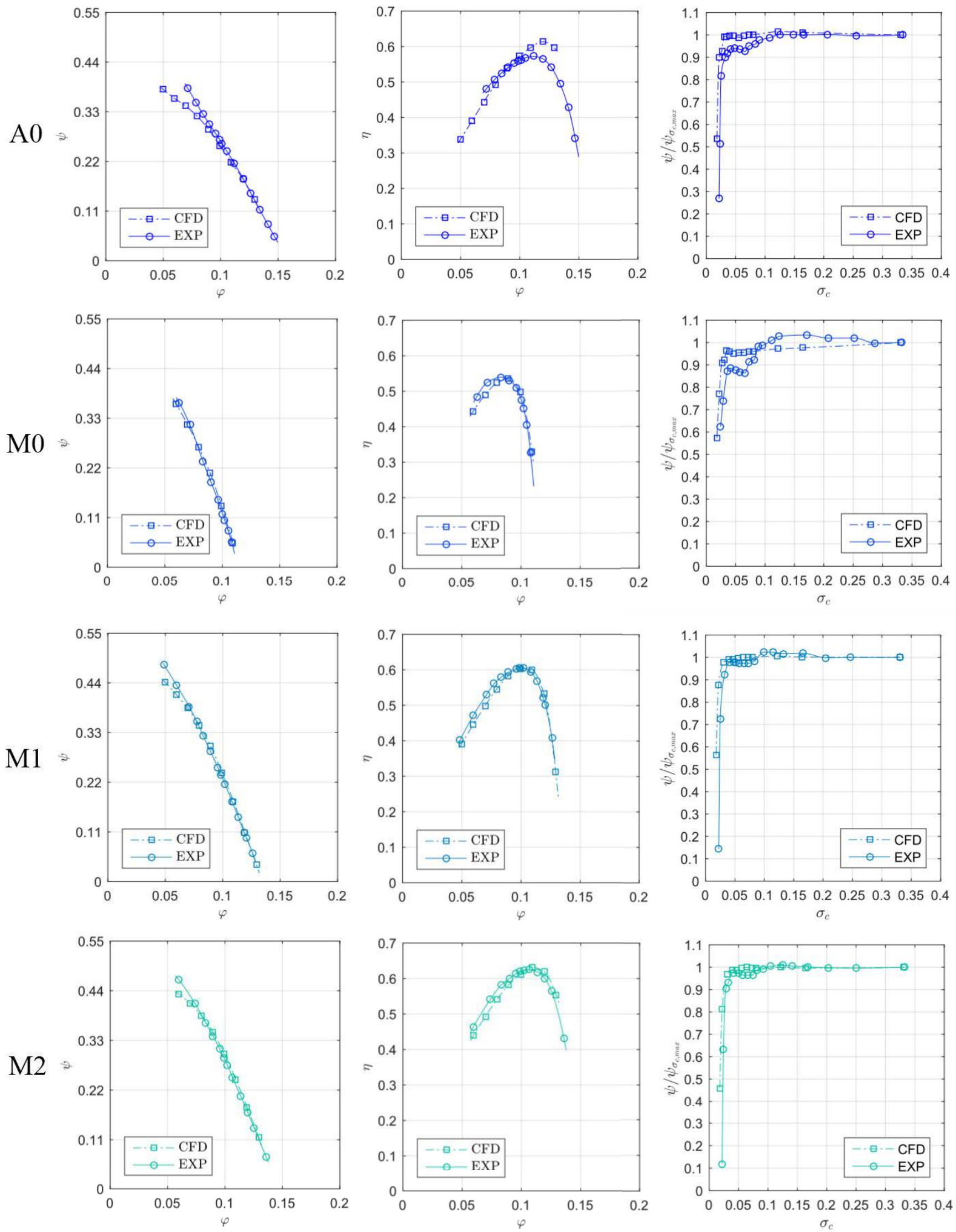

Figure 7. Comparison of CFD and EXP at $18000 \mathrm{rpm}$ 
Figure 11 to 14 shows the flow conditions at $\sigma_{c} \approx 0.04$ during the test runs compared to CFD. It can be seen that before the head begins to drop much cavitation is already existing. To visualize cavitation in CFD a vapor fraction of $40 \%$ is used. By comparing qualitatively the visible cavitation areas predicted by CFD and seen in the experiment a good agreement in terms of size and appearance of the vapor regions can be observed.
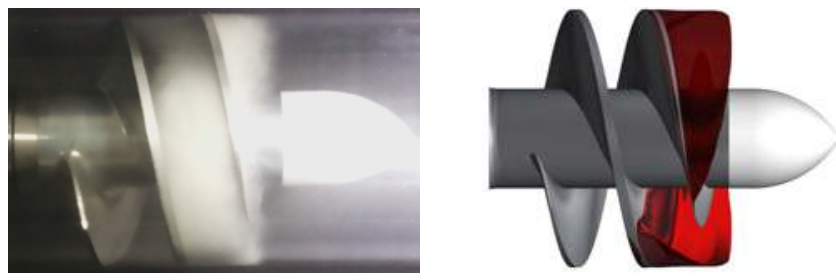

Figure 11. Ao Suction performance $\left(\sigma_{c} \approx 0.04\right)$
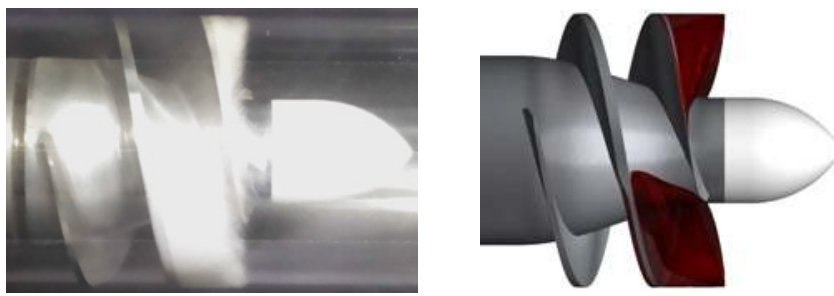

Figure 12. Mo Suction performance $\left(\sigma_{c} \approx 0.04\right)$
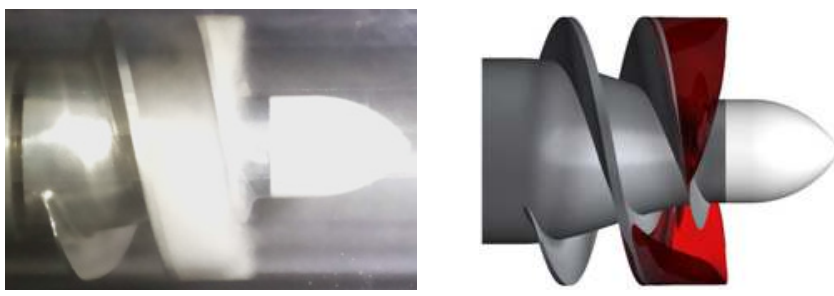

Figure 13. M1 Suction performance $\left(\sigma_{c} \approx 0.04\right)$
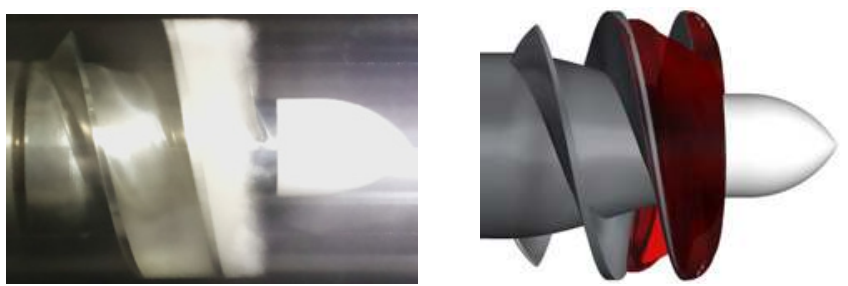

Figure 14. M2 Suction performance $\left(\sigma_{c} \approx 0.04\right)$

A visualization for the design point during the performance measurement is shown in figure 15 for inducer Mo. All other variants exhibit a similar behavior. Upstream of the blade leading edge tip a vapor region can be observed.

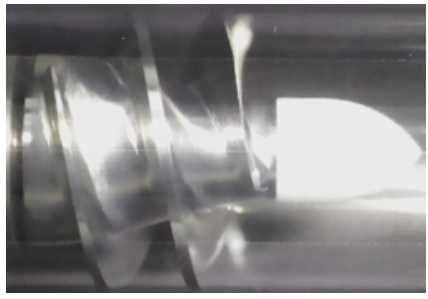

Figure 15. Mo Designpoint $(\varphi=0.1)$

\subsection{Influence of rotating speed}

In figure 16, 17 and 18 a comparison of the results of CFD and experiments at $24000 \mathrm{rpm}$ for inducer Ao is shown. The overall progression of head coefficient and efficiency is similar to the ones seen at $18000 \mathrm{rpm}$. In part load a reduction in slope of the head characteristic curve is predicted by CFD which cannot be observed in the experimental results. Comparing suction performance results of CFD simulations and experiments, it is obvious that in case of the experiment the head drop occurs at higher values of $\sigma_{c}$. Consequently the point of $10 \%$ drop in head coefficient, already included in table 4 , is predicted at a lower value of cavitation number in case of the CFD simulation.

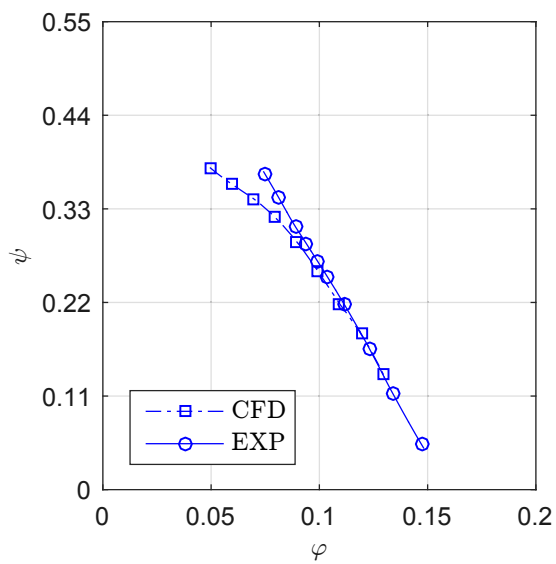

Figure 16. Ao - Head coefficient at $24000 \mathrm{rpm}$

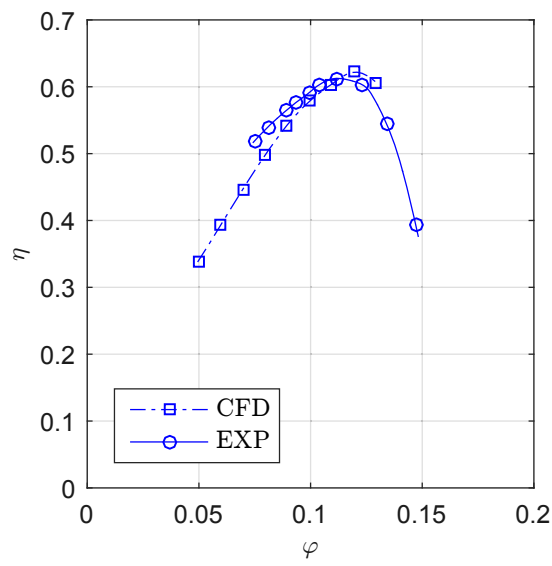

Figure 17. Ao - Efficiency at $24000 \mathrm{rpm}$ 


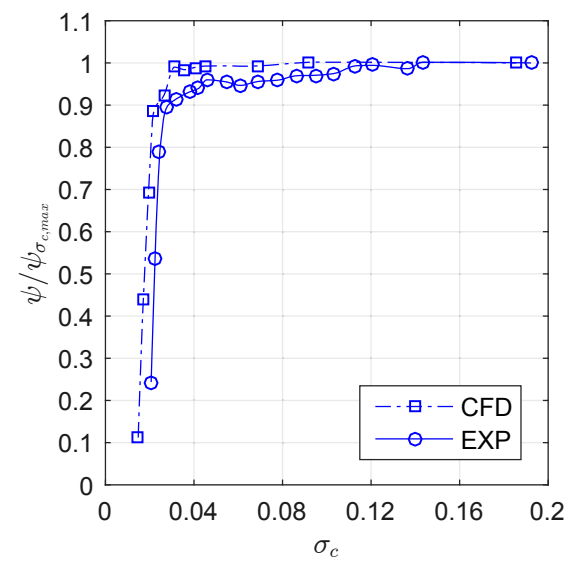

Figure 18. Ao - Suction performance at $24000 \mathrm{rpm}$

In figures 19, 20 and 21 the comparison of performance results at different rotating speeds is depicted. The different rotating speeds are marked with $18 \mathrm{k}$ for $18000 \mathrm{rpm}$ and $24 \mathrm{k}$ for $24000 \mathrm{rpm}$ in each diagram. Evidently, the results at $24000 \mathrm{rpm}$ and $18000 \mathrm{rpm}$ show that there is no visible influence of rotating speed on the head coefficient and a minor influence on efficiency. The efficiency at $24000 \mathrm{rpm}$ is generally higher. Rotating speed also shows little influence on suction performance as can be seen in figure 21. For all experimental investigations already presented, pictures have been taken for each operation point during the test runs. Some examples are shown for the suction performance test of inducer Ao. Pictures are taken at a rotating speed of $24000 \mathrm{rpm}$ and a flow coefficient of $\varphi=0.1$. Beginning with the maximum $\sigma_{c}$ a continuously growth of cavitation can be observed while decreasing the cavitation number. The blade passage of the inducer is almost full of cavitation at a value of $\sigma_{c}=0.028$ where the head coefficient begins to drop rapidly. At $\sigma_{c}=0.021$ the point at which almost total breakdown of head can be observed cavitation also exists behind the outlet of the inducer.

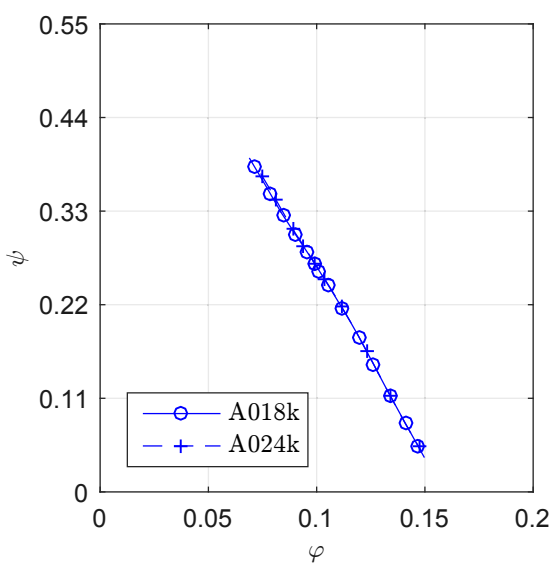

Figure 19. Ao - Head coefficient (Experiment)

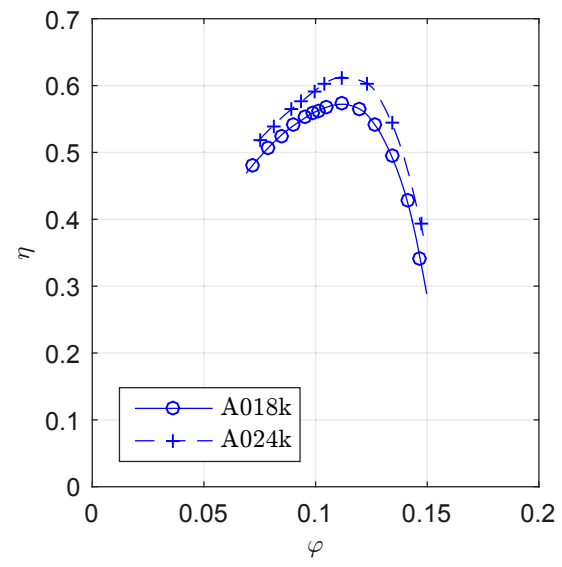

Figure 2o. Ao - Efficiency (Experiment)

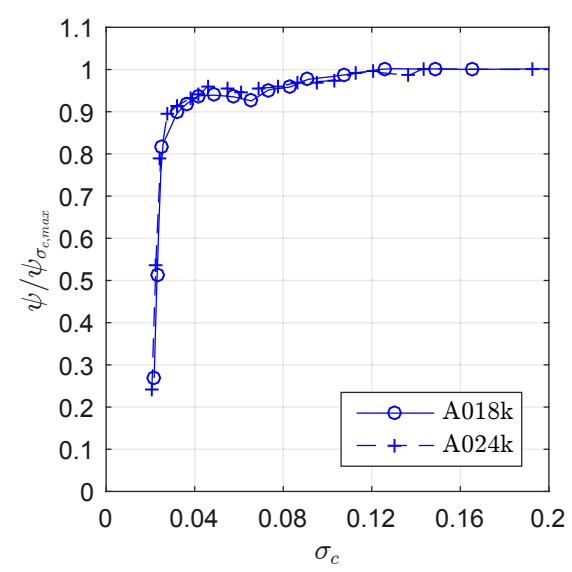

Figure 21. Ao - Suction performance (Experiment)

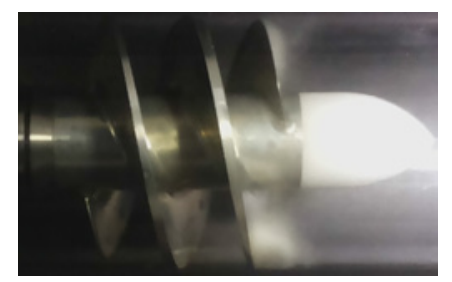

Figure 22. $\mathrm{AO}_{24} \mathrm{k}$ Suction performance $\left(\sigma_{c}=0.192\right)$

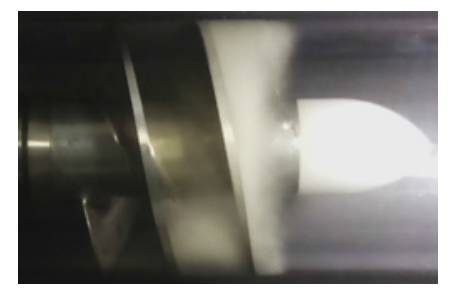

Figure 23. $\mathrm{AO}_{24} \mathrm{k}$ Suction performance $\left(\sigma_{c}=0.048\right)$ 


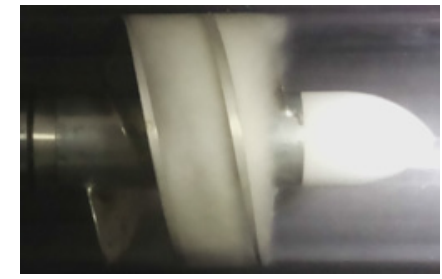

Figure 24. $\mathrm{AO}_{24} \mathrm{k}$ Suction performance $\left(\sigma_{c}=0.0275\right)$

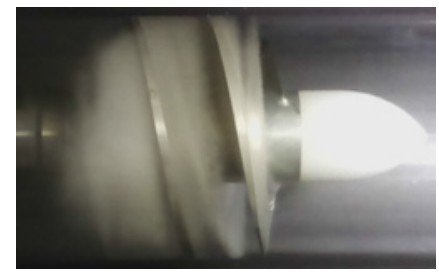

Figure 25. $\mathrm{AO}_{24} \mathrm{k}$ Suction performance $\left(\sigma_{c}=0.0207\right)$

\section{DISCUSSION}

Results of numerical simulations and experimental investigations of four different inducers operating at high rotational speeds have been compared. It is shown that CFD simulations can be used to estimate non-cavitating performance behavior at operating conditions close to the design point. For all of the inducers under consideration good agreement between CFD simulation and experiment could be observed near this point. At off-design conditions, especially in part load, the discrepancy between simulation and experiment is getting larger. To evaluate the different inducer designs the data from experiment is used. The inducer with constant hub diameter, named Ao, shows a lower efficiency compared to inducers with increasing hub diameter and adjusted blade angle distribution at the trailing edge. The head coefficient curve is flatter for the inducer Ao so the operating range is larger than for the inducers with increasing hub diameter. Only increasing the exit hub diameter of this inducer, as is done for inducer Mo, leads to a reduction in head coefficient and efficiency. Hence the blade angle distribution at the trailing edge has to be adapted to improve head coefficient and efficiency for inducers with increasing hub diameter. Two possible modifications of blade angle are realized for inducers $\mathrm{M}_{1}$ and M2. As a result of this modification not only the performance can be improved but also the best point of efficiency can be moved closer to the design point for the inducers $\mathrm{M}_{1}$ and $\mathrm{M}_{2}$. In case of the suction performance substantial deviation between the numerical and experimental data are found independently of the inducer design under investigation. Therefore the simulation results can only be regarded as a first guess of cavitation behavior. To perform a quantitative analysis of cavitating inducers calibration of the applied cavitation model is necessary. This can only be done by using experimental data.

Looking at different rotating speeds there seems to be no visible influence on the head coefficient. There is a small but not negligible influence of rotating speed on suction performance. This influence for $\sigma_{c}$ where $10 \%$ drop of head coefficient occurs can be seen in table 4 . For experiments $\sigma_{c}$ decrease with higher rotational speed. However it has to be taken into account that the reduced speed is still a high rotational speed. Further investigations must show how far the speed can be reduced until an apparent influence can be recognized.

\section{ACKNOWLEDGMENTS}

The authors would like to thank the Federal Ministry for Economic Affairs and Energy (BMWI) and the German Aerospace Center (DLR) for the support of the present work. The simulations were conducted on the high performance cluster Elwetritsch at TU Kaiserslautern, which is part of the Alliance of High Performance Rheinland-Pfalz (AHRP).

\section{NOMENCLATURE}

\section{Latin symbols}

$\begin{array}{ccc}\text { Symbol } & \text { Description } & \text { Unit } \\ A & \text { Area } & \mathrm{m}^{2} \\ D & \text { Diameter } & \mathrm{m} \\ H & \text { Head } & \mathrm{m} \\ L & \text { Length } & \mathrm{m} \\ M & \text { Torque } & \mathrm{Nm} \\ N P S H & \text { Net positive suction head } & \mathrm{m} \\ T & \text { Temperature } & \mathrm{K} \\ Q & \text { Volume flow } & \mathrm{m}^{3} \mathrm{~s}^{-1} \\ c & \text { Velocity } & \mathrm{ms}^{-1} \\ g & \text { Gravitational acceleration } & \mathrm{ms}^{-2} \\ n & \text { Rotating speed } & \mathrm{s}^{-1} \\ p & \text { Pressure } & \mathrm{Pa}^{-1} \\ u & \text { Circumferential velocity } & \mathrm{ms}^{-1}\end{array}$

\section{Greek symbols}

$\begin{array}{ccc}\text { Symbol } & \text { Description } & \text { Unit } \\ \alpha_{w} & \text { Wedge angle } & \circ \\ \beta & \text { Angle } & \circ \\ \eta & \text { Efficiency } & - \\ \omega=2 \pi n & \text { Angular velocity } & \mathrm{rads}^{-1} \\ \Psi & \text { head coefficient } & - \\ \varphi & \text { Flow coefficient } & - \\ \Omega_{s s} & \text { Suction specific speed } & - \\ \rho & \text { Density } & \mathrm{kgm}^{-3} \\ \sigma_{c} & \text { Cavitation number } & -\end{array}$




\section{Indices}

$\begin{array}{cc}\text { Symbol } & \text { Description } \\ 1 & \text { Intake } \\ 2 & \text { Outtake } \\ \text { b } & \text { Blade } \\ \text { d } & \text { Design point } \\ \text { h } & \text { Hub } \\ \text { m } & \text { Middle } \\ \text { s } & \text { Shroud } \\ \text { t } & \text { Tip } \\ \text { tot } & \text { Total } \\ \text { v } & \text { Vapor }\end{array}$

\section{Acronyms}

$\begin{array}{cc}\text { CFD } & \text { Computational fluid dynamics } \\ \text { EXP } & \text { Experiment } \\ \text { LE } & \text { Leading edge } \\ \text { P } & \text { Plane } \\ \text { TE } & \text { Trailing edge } \\ \max & \text { Maximum }\end{array}$

\section{REFERENCES}

[1] B. Lakshminarayana. Fluid Dynamics and Heat Transfer of Turbomachinery. John Wiley \& Sons, New York, 1995.

[2] C.E. Brennen. Hydrodynamics of Pumps. Oxford University Press, 1994.

[3] D. Japikse, W.D. Marscher, and R.B. Furst. Centrifugal Pump Design and Performance. Concepts ETI, Inc., 1997.

[4] L. d'Adostino, L. Torre, A. Pasini, and A. Cervone. On the preliminary design and noncavitation performance prediction of tapered axial inducers. Fournal of Fluids Engineering, 130:111303-1-1-111303-8, 2008.

[5] K. J. Jakobsen. Liquid Rocket Engine Turbopump Inducers, volume NASA SP-8052 of NASA Space Vehicle Design Criteria. NASA, 1971.

[6] D. A. Ehrlich, J. A. Schwille, R. P. Welle, J. W. Murdock, and B. S. Hardy. A water test facility for liquid rocket engine turbopump cavitation testing. Proceedings of the 7th International Symposium on Cavitation, 2009. Paper No. 11.

[7] D. A. Ehrlich and J. W. Murdock. A dimensionless scaling parameter for thermal effects on cavitation in turbopump inducers. Fournal of Fluids Engineering, 137(4):041103-1-041103-8, 2015.

[8] E. Rapposelli, A. Cervone, and L. d'Agostino. A new cavitating pump rotordynamic test facility. Proceedings of the 38th AIAA foint Propulsion Conference and Exhibit, 2002. Paper No. 2002-4285.

[9] T. Hashimoto, M. Yoshida, M. Watanabe, K. Kamijo, and Y. Tsujimoto. Experimental study on rotating cavitation of rocket propellant pump inducers. Journal of Propulsion and Power, 13(4):488-494, 1997.
[10] F. Bakir, S. Kouidri, R. Noguera, and R. Rey. Experimental analysis of an axial inducer influence of the shape of the blade leading edge on the performances in cavitating regime. Journal of Fluids Engineering, 125(2):293-301, 2003.

[11] D. Japikse. Overview of industrial and rocket turbopump inducer design. The gth International Symposium on Transport Phenomena and Dynamics of Rotating Machinery, 2001.

[12] J. F. Gülich. Kreiselpumpen. Springer, 2013.

[13] DIN EN ISO 9906:2012. Rotodynamic pumps - hydraulic performance acceptance tests. 